\title{
Genetic evidence of the programming of beta cell mass and function by glucocorticoids in mice
}

\author{
B. Valtat $\cdot$ C. Dupuis $\cdot$ D. Zenaty $\cdot$ A. Singh-Estivalet $\cdot$ \\ F. Tronche $\cdot$ B. Bréant $\cdot$ B. Blondeau
}

Received: 25 March 2010 / Accepted: 3 August 2010 /Published online: 21 September 2010

(C) Springer-Verlag 2010

\begin{abstract}
Aims/hypothesis Prenatal exposure to excess glucocorticoids associates with low birthweight in rodents, primates and humans and its involvement in programming glucose homeostasis is suspected. Our aim was to further dissect the role of glucocorticoids on beta cell development and function in mice.

Methods Using the model of maternal general food restriction during the last week of pregnancy, we thoroughly studied in the CD1 mouse-mothers and fetal and adult offspring - the pancreatic, metabolic and molecular consequences of maternal undernutrition associated with excess glucocorticoids. The specific involvement of the glucocorticoid receptor (GR) was studied in mutant fetuses lacking GR in pancreatic precursors or mature beta cells.

Results Maternal general food restriction in the mouse is associated with decreased maternal glucose and increased corticosterone levels. Fetuses from underfed dams had increased corticosterone levels, decreased pancreatic endocrine gene expression but increased exocrine gene expression and a lower beta cell mass. The offspring of these dams had a low birthweight, permanent postnatal growth retardation and, as adults, impaired glucose tolerance, decreased beta cell mass
\end{abstract}

B. Valtat $\cdot$ C. Dupuis $\cdot$ D. Zenaty $\cdot$ A. Singh-Estivalet $\cdot$

B. Bréant $(\bowtie) \cdot B$. Blondeau

INSERM UMR-S 872, Centre de Recherche des Cordeliers,

15 rue de l'Ecole de Médecine,

75006 Paris, France

e-mail: bernadette.breant@crc.jussieu.fr

B. Valtat $\cdot$ C. Dupuis $\cdot$ D. Zenaty $\cdot$ A. Singh-Estivalet $\cdot$

F. Tronche $\cdot$ B. Bréant $\cdot$ B. Blondeau

University Pierre and Marie Curie,

Paris, France

F. Tronche

CNRS UMR 7224-INSERM U952,

Paris, France
$(-50 \%)$ and massively reduced islet expression $(-80 \%)$ of most of the genes involved in beta cell function (e.g. $P d x$, Sur1 [also known as $A b c c 8$ ], insulin). Moreover, using mutant fetuses lacking GR in pancreatic precursors or beta cells we show that the deleterious effect of undernutrition on fetal beta cell development requires the presence of the GR in pancreatic precursor cells.

Conclusions/interpretation These results demonstrate the crucial role of excess fetal glucocorticoids and the importance of GR signalling in progenitor cells to programme beta cell mass and dysfunction.

Keywords Beta cells · Fetal programming .

Glucocorticoids · Insulin secretion · Islets

\begin{tabular}{|c|c|}
\hline \multicolumn{2}{|c|}{ Abbreviations } \\
\hline $\mathrm{AUC}_{\mathrm{g}}$ & Area under the curve for glucose $0-120 \mathrm{~min}$ \\
\hline BrdU & Bromodeoxyuridine \\
\hline DEXA & Dual-energy X-ray absorptiometry \\
\hline $\mathrm{E}$ & Embryonic day \\
\hline GFR & General food restriction \\
\hline GR & Glucocorticoid receptor \\
\hline $\mathrm{GR}^{\mathrm{lox} / \mathrm{lox}}$ & Control mice (with GR) \\
\hline $\mathrm{GR}^{\mathrm{PdxCre}}$ & $\begin{array}{l}\text { Mouse lacking the GR in pancreatic precursor } \\
\text { cells }\end{array}$ \\
\hline $\mathrm{GR}^{\mathrm{RIPCre}}$ & Mouse lacking the GR in mature beta cells \\
\hline ipGTT & Intraperitoneal glucose tolerance test \\
\hline IUGR & Intrauterine growth retardation \\
\hline PP & Pancreatic polypeptide \\
\hline
\end{tabular}

\section{Introduction}

The concept of the early-life origins of adult diseases or fetal programming describes the process whereby a factor at a critical or sensitive window of development exerts effects that 
persist throughout life. Prenatal exposure to an adverse environment permanently affects organ and tissue structure and function and ultimately leads to increased susceptibility to complex metabolic disorders. In fact, low birthweight-a general feature of fetal undernutrition - is strongly associated with a higher risk of developing chronic diseases such as type 2 diabetes and cardiovascular disease [1-4]. Recent evidence pinpoints a role for glucocorticoids as a causal link between intrauterine growth retardation (IUGR) and the increased risk of developing glucose intolerance and type 2 diabetes in adulthood [5, 6]. In humans [7] and rodents [8-11], fetal exposure to excess maternal glucocorticoids causes low birthweight. It is also associated with the later impairment of glucose tolerance and hypertension in rats and monkeys [8-13]. A link between glucocorticoid elevation, low birthweight and beta cell development was identified in a rat model of maternal general food restriction (GFR) leading to decreased beta cell mass and the later occurrence of glucose intolerance in adults $[14,15]$. In this model we showed that maternal GFR induces a rise in both maternal and fetal corticosterone levels [9], which is responsible for the decreased beta cell mass and islet numbers in the rat fetus [8]. Conversely, in normally fed rat fetuses, low corticosterone levels were associated with high beta cell numbers [8]. More recently, by inactivation of the gene encoding the glucocorticoid receptor (GR) in specific pancreatic cell populations in the mouse we showed that the effects of glucocorticoids on pancreas development indicate a decisive role of the GR on pancreatic precursor cells, as its deletion led to a twofold increase in beta cell mass in adult mice [16].

However, the extent to which the deleterious effects of undernutrition on beta cell development can be ascribed to the activation of the glucocorticoid signalling pathway and more specifically to GR activation, or to other factors modified by the maternal nutritional status, remains unknown. To provide definitive evidence, we turned to genetic mouse models of GR gene deletion, with the prior verification that the GFR model also induced maternal and fetal glucocorticoid elevation and deleterious pancreatic consequences in the mouse. Therefore, the effects of GFR on maternal hormonal and blood glucose levels, as well as the pancreatic, metabolic and molecular consequences in the fetal and postnatal offspring were thoroughly studied in the CD1 mouse until adulthood. The key role of glucocorticoid signalling in the effects of food restriction on beta cell development was studied in mutant fetuses lacking the GR either in pancreatic precursors ( $\mathrm{GR}^{\mathrm{PdxCre}}$ mouse fetuses) or in mature beta cells (GR ${ }^{\mathrm{RIPCre}}$ mouse fetuses).

\section{Methods}

Mice and food-restriction protocol CD1 Swiss pregnant mice from Charles River Laboratories (l'Arbresle, France) had their food restricted from embryonic day (E)11.5 until E18.5 (50\% of the control daily food intake, approximately $3 \mathrm{~g} /$ day). At parturition, food-restricted dams and their pups were fed ad libitum. Mice born from food-restricted mothers are referred to as F1-IUGR mice whereas those born from normally fed mothers are termed F1-control mice. Pregnant females were killed by decapitation at days 14.5 (E14.5), E15.5, E16.5 and E18.5 of pregnancy and the fetuses were collected. Maternal plasma glucose levels were measured immediately using a glucometer (Freestyle Papillon Mini, Abbott, Rueil-Malmaison, France) and maternal and fetal plasma corticosterone levels were measured by enzyme immunoassay (AssayMax Corticosterone ELISA kit, Abcys, Paris, France). Adult mice that lack the $\mathrm{GR}$ in pancreatic precursors $\left(\mathrm{GR}^{\mathrm{PdxCre}}\right)$ or in mature beta cells $\left(\mathrm{GR}^{\mathrm{RIPCre}}\right)$ have been previously described by Gesina et al. [16]. Controls, i.e. $\mathrm{GR}^{\text {lox/lox }}$ female mice, were mated with either $\mathrm{GR}^{\mathrm{PdxCre}}$ or $\mathrm{GR}^{\mathrm{RIPCre}}$ males. Food restriction was imposed on these pregnant $\mathrm{GR}^{\text {lox/lox }}$ mice from E11.5 until E18.5, as described above. Fetuses were collected on day 18.5 of pregnancy, weighed and their pancreases dissected. Morphometric measurements of beta cell fraction were performed as described below, except that the head and tail were not separated. For proliferation measurements, pregnant mice were injected $2 \mathrm{~h}$ before they were killed with $50 \mathrm{mg} / \mathrm{kg}$ bromodeoxyuridine (BrdU; Sigma-Aldrich, Lyon, France). Proliferation was assessed after co-staining for insulin and BrdU and was expressed as the percentage of cells positive for insulin and BrdU over the total number of insulin cells, as previously described by Avril et al. [17].

All experiments were carried out according to the principles of laboratory animal care and the French law, Authorisation no. 75-1435 received by B. Valtat from the French Ministry of Agriculture.

Intraperitoneal glucose tolerance test (ipGTT) F1-control and F1-IUGR mice were submitted to a $16 \mathrm{~h}$ fast at 3 months of age. Blood was collected at time zero and at 15, 30, 60 and $120 \mathrm{~min}$ after an intraperitoneal injection of glucose $(2 \mathrm{~g} / \mathrm{kg}$ body weight). Plasma glucose levels were measured at all time points and the area under the glucose curve (AUCg) was calculated. Serum insulin levels were measured at time zero and at 15 min by ELISA (Mercodia, Uppsala, Sweden).

Insulin tolerance test Insulin was injected intraperitoneally at $1 \mathrm{U} / \mathrm{kg}$ body weight after a $5 \mathrm{~h}$ fast. Blood glucose levels were measured before and 15, 30, 60 and 120 min after the insulin injection. Plasma glucose levels were measured as described above.

Body composition Body composition was measured in the offspring by dual-energy X-ray absorptiometry (DEXA) 
using the Lunar PIXImus Mouse Densitometer (GE Healthcare, Madison, WI, USA). Mice were anaesthetised with a mixture of ketamine $(85 \mathrm{mg} / \mathrm{kg})$ and xylazine $(8.5 \mathrm{mg} / \mathrm{kg})$, administered intraperitoneally.

Pancreas processing and quantitative morphometry Pancreases from E18.5 fetuses and adult mice were dissected (five for each nutritional condition and each genotype when mutant fetuses were analysed), fixed, sectioned and prepared for immunohistochemistry performed on an Autostainer (Dako, Trappes, France) using anti-insulin antibody (Dako) followed by incubation with secondary antibodies coupled to peroxidase (Immunotech, Marseilles, France) and revealed using diaminobenzidine (DAB). In adult pancreases, the head and tail were analysed separately. Beta cell fraction was measured by morphometric measurements on eight sections per pancreas (four from the head, four from the tail or eight total from fetal pancreases) as previously described by Gesina et al. [16]. Alpha cell fraction was similarly measured at E18.5 and adult age after immunohistochemical staining with anti-glucagon antibodies (Sigma-Aldrich).

Mouse islet isolation Collagenase at $1 \mathrm{mg} / \mathrm{ml}$ (SigmaAldrich) was diluted in HBSS (Hanks' balanced salt solution) and injected in the bile duct after occlusion of the distal end just proximal to the duodenum. Pancreases were dissected out and incubated at $37^{\circ} \mathrm{C}$ for $20 \mathrm{~min}$. After strong manual shaking, pancreatic tissue was washed four times and decanted on ice in 10\% FBS HBSS. Islets were handpicked under a binocular microscope (Leica Microsystems, Wetzlar, Germany) and washed in PBS before RNA extraction.

RNA preparation and real-time PCR Total RNA was extracted from fetal pancreases and isolated adult islets using RNeasy Plus extraction kit (Qiagen, Courtaboeuf, France) according to the manufacturer's guidelines. RNA samples were reverse transcribed into cDNA using Superscript II reverse transcriptase (Invitrogen, Cergy Pontoise, France). Gene expression was quantified by real-time PCR with SybrGreen supermix in a MyIQ thermocycler (Biorad, Marnes-la-Coquette, France). Samples of islet cDNA from control mice were diluted and used to produce a standard curve. Gene expression was normalised to $18 \mathrm{~S}$ ribosomal RNA. Primers were designed to span two exons when possible. Primers sequences are available upon request.

Statistical analysis All results are expressed as means \pm SD. The statistical significance of variations was tested by a Mann-Whitney non-parametric test; $p<0.05$ was considered significant.

\section{Results}

Perturbed maternal environment causes overexposure to glucocorticoids and growth retardation in the offspring Restricting by $50 \%$ the general food intake of pregnant mice during the last week of pregnancy resulted in decreased maternal blood glucose levels by day 14.5 of pregnancy that persisted throughout pregnancy (Fig. 1a), whereas serum corticosterone levels were increased by $60 \%$ at the same stages of pregnancy ( $p<0.05$; Fig. 1b). During pregnancy, control pregnant mice gained weight while the weight of food-restricted dams remained stable from E11.5, the beginning of undernutrition (Fig. 1c). From E14.5 to E18.5, fetuses of food-restricted dams showed a lower body weight than fetuses from control females (Fig. 1d). Placental weight at E18.5 was also decreased (132 \pm $11.8 \mathrm{mg}$ vs $99.7 \pm 5.7 \mathrm{mg}, p<0.05)$. Growth retardation was apparent at birth (body weight $1.2 \pm 0.16 \mathrm{~g}$ vs $1.75 \pm$ $0.12 \mathrm{~g}$ in controls, $p<0.05$ ), and persisted at the postnatal stage (Fig. 1e) and until the adult stage in F1-IUGR offspring born from food-restricted mothers, both in females and males (Fig. 1f-g). Undernutrition did not affect litter size either at the fetal stages or at birth.

Consequences of IUGR on fetal pancreas at E18.5 As pregnant mice subjected to food restriction had increased corticosterone levels, we measured the placental expression of the gene encoding 11-beta-hydrosteroid dehydrogenase type 2 (Hsd11b2), the enzyme that protects the fetus from excess maternal glucocorticoid concentrations and fetal corticosterone levels. The production of this enzyme was dramatically decreased in the placentas of fetuses from food-restricted mice (Fig. 2a), which showed strongly increased corticosterone levels (Fig. 2b), demonstrating that at the end of pregnancy the fetuses were exposed to excess glucocorticoid concentrations. In this hormonal context, these fetuses showed a $50 \%$ decrease in beta cell fraction (Fig. 2c) as well as a reduction in the pancreatic expression of Ins 2 and pro-endocrine genes such as $P d x 1$, Sox9 and Ngn3 (also known as Neurog3; Fig. 2d); conversely, expression of exocrine genes (Ptfla, amylase and carboxypeptidase A [ $\mathrm{Cpa} 2]$ ) and of the gene encoding the GR was strongly increased. Alpha cell fraction showed a tendency to be decreased in E18.5 fetuses from foodrestricted mice $(0.13 \pm 0.01 \%$ vs $0.16 \pm 0.02 \%$ in controls $)$, without reaching significant statistical difference $(p=0.08)$.

Metabolic consequences in F1-IUGR adult mice Levels of plasma glucose were higher in F1-IUGR mice in both the fasted state $(5.96 \pm 0.87$ vs $4.03 \pm 0.19 \mathrm{mmol} / 1$ in $\mathrm{F} 1$-controls, $p<0.01)$ and the fed state $(6.93 \pm 0.89$ vs $5.76 \pm 0.57 \mathrm{mmol} / 1$ in F1 controls, $p<0.05)$. To better characterise glucose homeostasis in these mice, intraperitoneal glucose tolerance 
$\mathbf{a}$

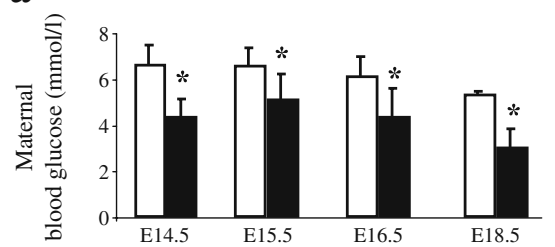

b

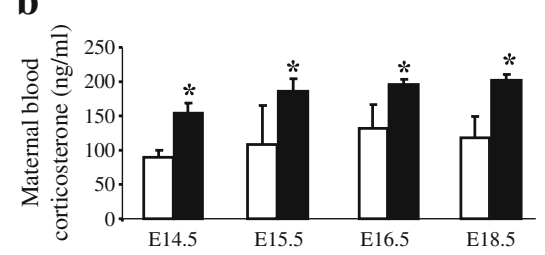

c

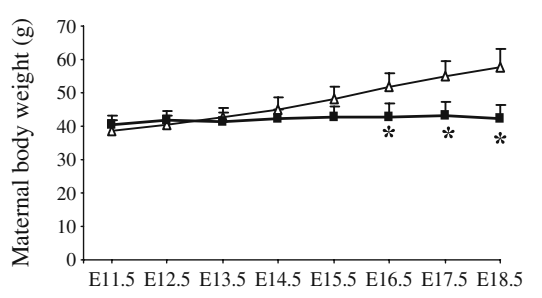

d

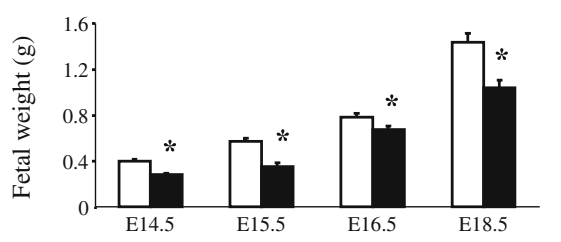

e

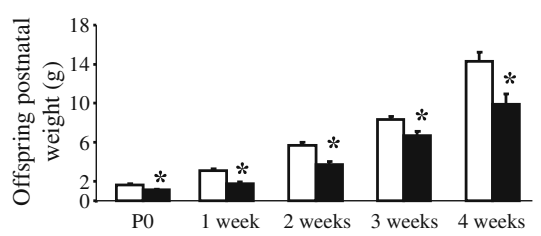

f

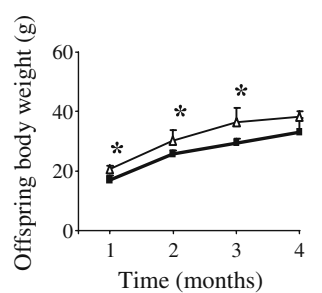

g

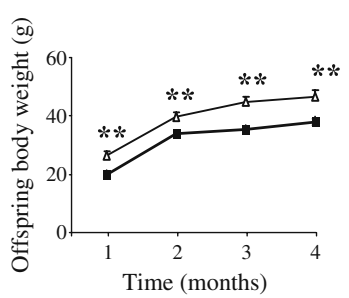

Fig. 1 Maternal food restriction increases maternal corticosterone levels and leads to irreversible growth retardation in offspring. (a) Plasma glucose and (b) corticosterone levels were measured in control (white bars) and food-restricted (black bars) pregnant females at day 14.5 of pregnancy (E14.5), E15.5, E16.5 and E18.5. c Average weight of control (white triangles) and food-restricted pregnant females (black squares) from E11.5. d Average weight of fetuses from control (white bars) and food-restricted (black bars) mice at different stages. e F1-control and F1-IUGR mice at birth and at 1, 2, 3 and 4 weeks of postnatal age. f, $\mathbf{g}$ F1-control and F1-IUGR mice at 1, 2, 3 and 4 months of age: (f) females and (g) males. All values are means \pm SD. ${ }^{*} p<0.05,{ }^{* *} p<0.01$ for food-restricted pregnant mice vs control pregnant mice or F1-IUGR (black bars) vs F1-controls (white bars) using the Mann-Whitney non-parametric test ( $n=6$ per group and stage of pregnancy or postnatal age)

measures in the head and tail parts of the pancreas showed that both parts were affected (Table 1), though the effects were more significant in the tail part of the organ. Alpha cell mass was also decreased in IUGR adult animals $(0.26 \pm$ $0.04 \mathrm{mg}$ vs $0.45 \pm 0.09 \mathrm{mg}$ in controls, $p<0.05$ ).

Consequences of IUGR on islet gene expression We next investigated in the adult islets the consequences of fetal food restriction on the expression of mRNA encoding key genes essential to beta cell function. We observed dramatic reductions $(-80 \%)$ in the expression of genes involved in beta cell function, including Pdx1, Pax6, Isll, Nkx2.2 (also known as $N k x 2-2$ ), $N k x 6.1$ (also known as $N k x 6-1$ ), Kir6.2 (also known as Kcnj11) and Surl (also known as Abcc8, $p<$ 0.05 ; Fig. 5). Similarly, reduced levels of glucose response genes (Glut2 [also known as Slc2a2] and glucokinase) and the two genes encoding insulin (Ins1 and Ins2) were also observed. We noted no significant differences in the expression of genes encoding glucagon, somatostatin, pancreatic polypeptide (PP) or ghrelin.

$G R$ is required for the negative effects of glucocorticoid on beta cell development As maternal GFR generates gluco(Fig. 4f). Separate morphometric analyses of these pancreatic 

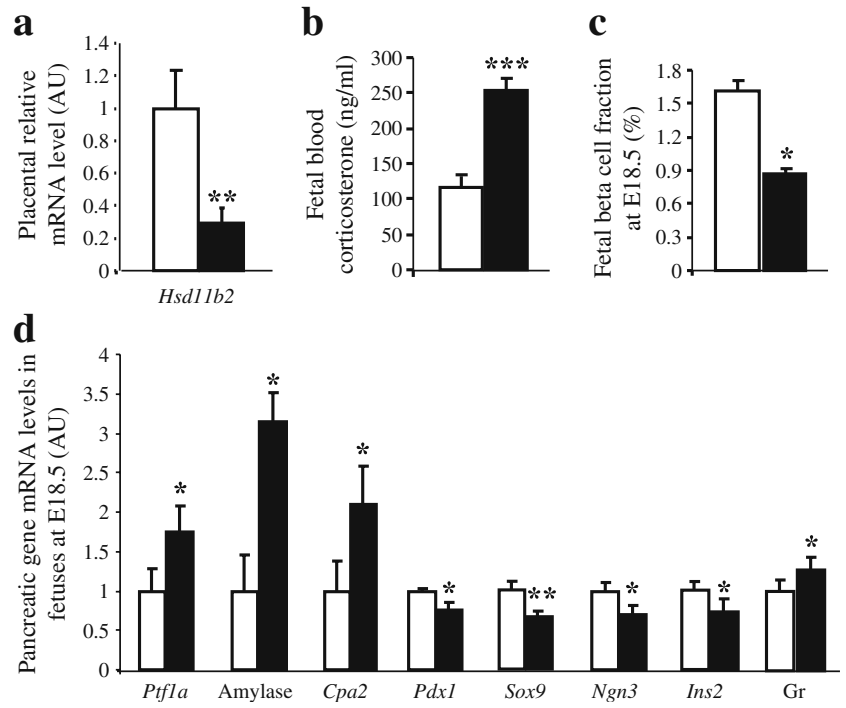

Fig. 2 Maternal undernutrition impairs fetal endocrine but favours exocrine pancreas development. a Placental expression of $H s d 11 b 2$ was measured in placenta at stage E18.5. b Corticosterone levels were measured in control (white bars) and food-restricted (black bars) fetuses at E18.5. c Beta cell fraction at E18.5 was measured morphometrically after immunohistochemistry for insulin on pancreatic sections from control (white bars) and food-restricted (black bars) fetuses. d Expression of both exocrine and endocrine genes was measured in the pancreases of fetuses at E18.5 by real-time PCR. Gene expression was normalised to control pancreas values. All values are means \pm SD. ${ }^{*} p<0.05,{ }^{* *} p<0.01,{ }^{* * *} p<0.001$, when comparing fetuses from food-restricted (black bars) mice with fetuses from control (white bars) mice using the Mann-Whitney non-parametric test ( $n=5$ per group for placental and pancreas gene expression; $n=4-5$ fetuses per pregnant female for corticosterone levels; $n=3$ for beta cell fraction)

corticoid excess, which is associated with a decreased beta cell mass and function in the offspring, we questioned whether the absence of glucocorticoid signalling through the GR would alter fetal beta cell development, and if so whether this development would be sensitive to the effects of maternal GFR. To this end we generated normally fed or underfed fetuses lacking the GR in either pancreatic precursor cells (called $\mathrm{GR}^{\mathrm{PdxCre}}$ ) or mature beta cells (called $\left.\mathrm{GR}^{\mathrm{RIPCre}}\right)$. Control $\left(\mathrm{GR}^{\text {lox/lox }}\right)$ females mated with either $\mathrm{GR}^{\mathrm{PdxCre}}$ or $\mathrm{GR}^{\mathrm{RIPCre}}$ males were subjected or not subjected to food restriction from day E11.5 of pregnancy. At E18.5, fetuses were collected from normally fed $\mathrm{GR}^{10 x / 10 x}$ or from food-restricted GFR-GR ${ }^{10 x / 10 x}$ females carrying half control (i.e. $\mathrm{GR}^{+}$) fetuses and half $\mathrm{GR}^{\mathrm{PdxCre}}$ or $\mathrm{GR}^{\mathrm{RIPCre}}$ fetuses. In line with $\mathrm{CD} 1$ mouse dams, the underfed $\mathrm{GR}^{\text {lox/lox }}$ dams (C57B1/6 background) showed 1.6-fold increased corticosterone concentrations compared with the normally fed $\mathrm{GR}^{10 x / l o x}$ dams (data not shown). Normally fed $\mathrm{GR}^{\mathrm{PdxCre}}$ mutant fetuses that lacked the GR in pancreatic precursors cells exhibited increased beta cell fraction at E18.5 compared with their control $\mathrm{GR}^{\text {lox/lox }}$ littermates (Fig. 6a). Normally fed GR ${ }^{\text {RIPCre }}$ mutant fetuses that had a GR deletion in mature beta cells showed a beta cell fraction similar to controls (Fig. 6a). Interestingly, increased beta cell fraction in $\mathrm{GR}^{\text {PdxCre }}$ fetuses was associated with a twofold increased beta cell proliferation compared with control fetuses, as shown by BrdU incorporation in beta cells (Fig. 6b-d). Thus, the absence of GR in pancreatic precursors, but not in mature beta cells, increases the fetal beta cell fraction, possibly through increased proliferation. We then asked if the effects of GFR, which include the development of excess glucocorticoid concentrations, would be mediated by the GR. In this abnormal hormonal environment, $\mathrm{GR}^{\text {lox/lox }}$ fetuses from underfed GFR females showed a decreased beta cell fraction vs those from normally fed females (Fig. 6a), confirming the deleterious effect of undernutrition on beta cell development. GR ${ }^{\text {RIPCre }}$ fetuses from underfed GFR females displayed a similarly decreased beta cell fraction compared with the normally fed mutant fetuses. In contrast, in GFR-GR ${ }^{\text {PdxCre }}$ fetuses with no GR in precursor cells, food restriction had no effect on beta cell fraction (Fig. 6a). This increased beta cell fraction was associated with a highly increased beta cell proliferation compared with their food-restricted GR ${ }^{\text {lox/lox }}$ littermates (Fig. 6b). These results clearly demonstrate that the deleterious effects of undernutrition-induced glucocorticoid excess on beta cell expansion require the presence of the GR in precursor cells. Interestingly, undernutrition reduced fetal body weight in all groups of fetuses irrespective of their genotype (Fig. 6e), underlining that suppression of glucocorticoid signalling in pancreatic precursor cells may protect and enhance beta cell mass but not fetal body weight during undernutrition.

As the majority of the mutant offspring of mice subjected to GFR did not survive after birth, the long-term metabolic and pancreatic consequences of fetal undernutrition in these mutants could not be assessed.

\section{Discussion}

Low birthweight is associated with increased susceptibility to chronic diseases such as diabetes and hypertension later in life. Prenatal exposure to excess glucocorticoids is suspected to be causal in the association between low birthweight and the programming of glucose homeostasis, at least in rodents and non-human primates [8, 12, 13]. More specifically, our hypothesis is that these hormones impair beta cell development and thereby later beta cell expansion and function. We adapted the rat model of maternal GFR to the mouse, with the aim of further dissecting the role of glucocorticoids in beta cell development using mutant mice. First we thoroughly studied, in CD1 mouse offspring, the fetal and long-term pancreatic, metabolic and molecular consequences of fetal undernutrition associated with overexposure to glucocorticoids. 


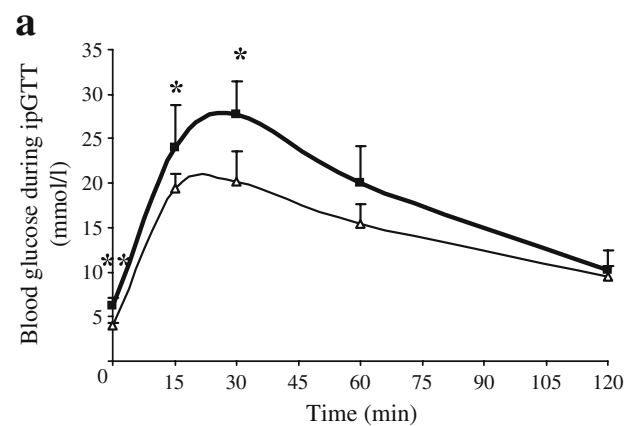

C

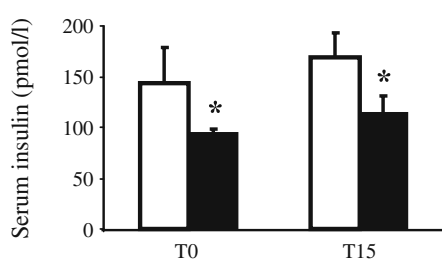

Fig. 3 Impaired glucose tolerance and insulin response in adult F1-IUGR offspring. a The intraperitoneal glucose tolerance test shows impaired glucose tolerance of F1-IUGR (black squares) compared with F1-control mice (white triangles). b $\mathrm{AUC}_{\mathrm{g}}$ of plasma glucose of F1-IUGR (black bar) and F1-control (white bar) mice. c Plasma insulin levels before and $15 \mathrm{~min}$ after glucose injection during the

The results reported here show that maternal general food restriction during the last week of pregnancy is associated with increased corticosterone levels and leads in the offspring to low birthweight, growth retardation, impairment of glucose tolerance, permanently decreased

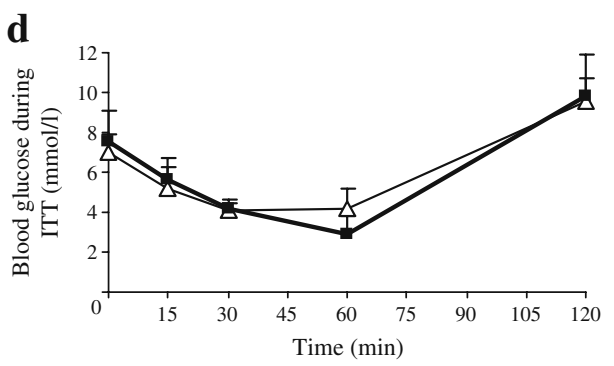

ipGTT. d The insulin tolerance test (ITT) shows similar insulin sensitivity in F1-control (white triangles) and F1-IUGR (black squares) mice. All values are means \pm SD. ${ }^{*} p<0.05,{ }^{*} p<0.01$ when comparing F1-IUGR with F1-control mice using the Mann-Whitney non-parametric test ( $n=6$ per group)

beta cell mass and reduced expression of several genes involved in beta cell function. Moreover, we show that the deleterious effect of undernutrition on fetal beta cell development associated with low birthweight requires the presence of the glucocorticoid receptor in pancreatic a

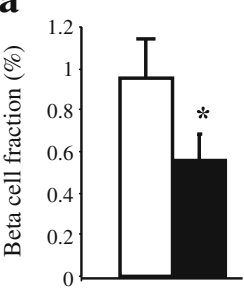

d

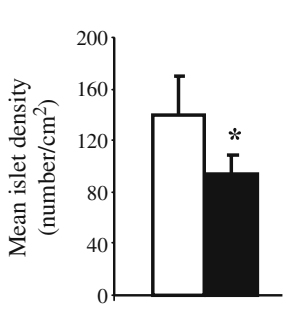

b

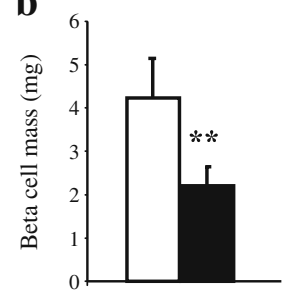

$\mathbf{e}$

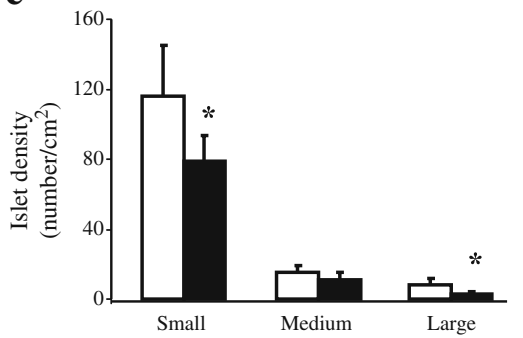

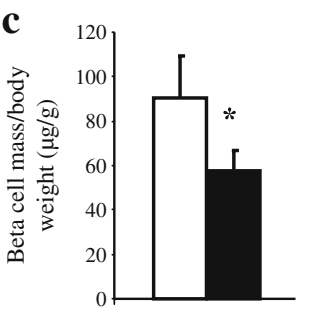

f

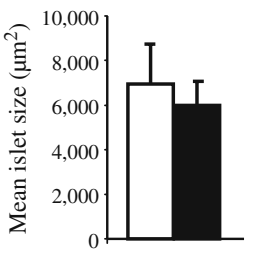

Fig. 4 Decreased beta cell mass and islet numbers in F1-IUGR mice. a Beta cell fraction was measured morphometrically on pancreatic sections from F1-control (white bars) and F1-IUGR (black bars) mice, as described in Methods. Beta cell mass, absolute (b) or relative to body weight (c), was profoundly decreased in F1-IUGR mice (black bars). The number of islets per $\mathrm{cm}^{2}$ which was morphometrically quantified from the same sections was also decreased (d), particularly the number of small and large islets (e), whereas mean islet size (f) remained unchanged in F1-IUGR mice. Results are expressed as means \pm SD. ${ }^{*} p<0.05,{ }^{*} p<0.01$ when comparing F1-IUGR with F1controls using the Mann-Whitney non-parametric test ( $n=6$ per group) 
Table 1 Comparative analysis of beta cell morphometrical variables in the head and the tail parts of the pancreases from adult F1-control and F1IUGR mice

\begin{tabular}{|c|c|c|c|c|}
\hline \multirow[t]{2}{*}{ Variable } & \multicolumn{2}{|l|}{ F1-control mice } & \multicolumn{2}{|l|}{ F1-IUGR mice } \\
\hline & Head & Tail & Head & Tail \\
\hline Beta cell fraction $(\%)$ & $0.87 \pm 0.12$ & $1.06 \pm 0.26$ & $0.62 \pm 0.11^{* *}$ & $0.53 \pm 0.22 *$ \\
\hline Beta cell mass (mg) & $1.75 \pm 0.20$ & $2.49 \pm 0.75$ & $1.20 \pm 0.38^{*}$ & $0.99 \pm 0.29 *$ \\
\hline Islet density (number/ $/ \mathrm{cm}^{2}$ ) & $146.9 \pm 50.3$ & $136.0 \pm 26.7$ & $101.3 \pm 14.7$ & $88.2 \pm 16.1^{* *}$ \\
\hline Small islet density (number $/ \mathrm{cm}^{2}$ ) & $125.68 \pm 50.66$ & $108.11 \pm 17.90$ & $85.11 \pm 17.27$ & $73.55 \pm 14.95^{*}$ \\
\hline Medium islet density (number $/ \mathrm{cm}^{2}$ ) & $14.42 \pm 5.08$ & $18.46 \pm 7.48$ & $11.60 \pm 2.67$ & $11.34 \pm 10.22$ \\
\hline Large islet density (number/ $/ \mathrm{cm}^{2}$ ) & $6.82 \pm 2.81$ & $9.38 \pm 6.04$ & $3.78 \pm 3.60$ & $2.65 \pm 1.96^{*}$ \\
\hline Islet size $\left(\mu \mathrm{m}^{2}\right)$ & $6,368.3 \pm 1,908.1$ & $7,807.9 \pm 1,610.2$ & $6,164.7 \pm 1,356.5$ & $5,864.4 \pm 1,757.4$ \\
\hline
\end{tabular}

Results are expressed as means $\pm \mathrm{SD}$

${ }^{*} p<0.05,{ }^{* *} p<0.01$ when comparing F1-IUGR with F1-control mice using the Mann-Whitney non-parametric test $(n=6)$

precursor cells. Altogether, these results demonstrate the role of excess fetal glucocorticoids and the importance of GR signalling in progenitors to programme later beta cell dysfunction.

Maternal food restriction in the CD1 mouse leads to increased maternal plasma corticosterone concentrations as early as 3 days after starting the restriction (embryonic day 14.5). The placental mRNA levels of Hsd11b2, encoding the enzyme which protects the fetus from excess maternal glucocorticoids, are greatly decreased and fetal plasma corticosterone concentrations are drastically increased at E18.5, demonstrating that fetuses are exposed to excess glucocorticoid concentrations. As in rats [8], fetal beta cell fraction is strongly decreased. Here, we propose that this decreased beta cell fraction results from a shift in the pancreatic differentiation process towards an exocrine fate, as underlined by the increased expression of genes encoding exocrine markers (Ptfla, amylase, carboxypeptidase A) and the decreased expression of genes encoding endocrine or pro-endocrine markers ( $P d x 1, \operatorname{Sox} 9, \mathrm{Ngn} 3$ and Ins 2). Thus, the alteration of beta cell fraction may arise from a decreased number of precursor cells expressing $N g n 3$ and $P d x 1$. These data are consistent with the modulation of the exocrine/endocrine differentiation balance by glucocorticoids previously shown by us in vitro using rat pancreatic buds treated with dexamethasone [16].

As the production of new beta cells in adulthood is low, any deficiency occurring in utero could compromise beta cell mass expansion, contributing to beta cell failure and favouring glucose intolerance later in life. This is indeed what happened in the adult offspring of the underfed mouse dams in this study. These offspring were hyperglycaemic,

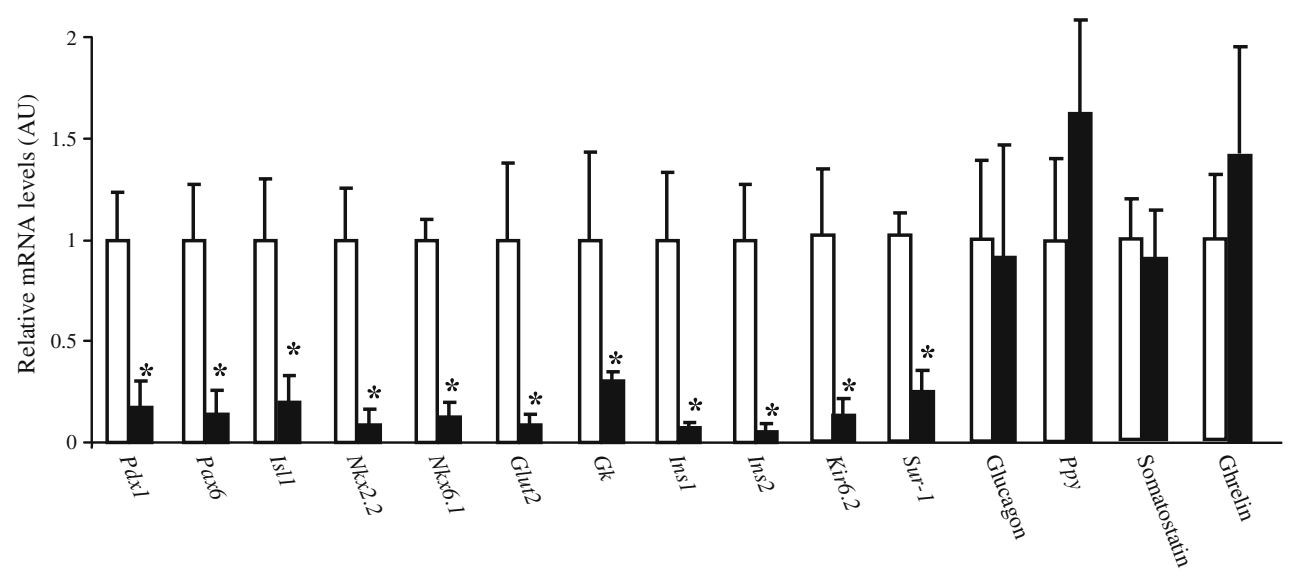

Fig. 5 Profound impairment of beta cell gene expression in islets from adult F1-IUGR mice. Beta cell gene expression was measured by real-time PCR from RNA extracted from F1-control (white bars) or F1-IUGR (black bars) mouse islets. Each gene was normalised to the $18 \mathrm{~S}$ internal control and gene expression values were thereafter normalised to control islet values. The expression of beta cell specific genes was deeply impaired but glucagon, somatostatin, PP (Ppy) and ghrelin expression remained unchanged in F1-IUGR islets. Results are expressed as means $\pm \mathrm{SD} ;{ }^{*} p<0.05$ when comparing F1-IUGR with F1-controls using the Mann-Whitney non-parametric test $(n=4$ animals per group) 

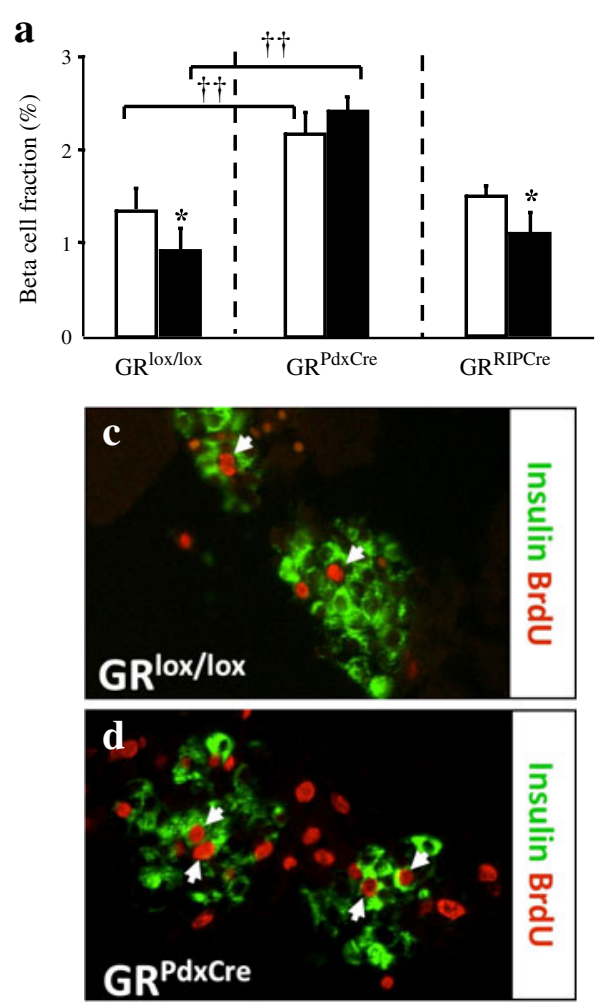

Fig. 6 The effect of maternal food restriction on beta cell development requires the presence of the GR in precursor cells. The consequences of $50 \%$ general food restriction (black bars) and normal diet (white bars) on pancreatic beta cell fraction (a), beta cell proliferation (b-d) and fetal body weight (e) at E18.5 in control fetuses $\left(\mathrm{GR}^{\text {lox/lox }}\right)$ and fetuses lacking the GR in pancreatic precursors $\left(\mathrm{GR}^{\mathrm{PdxCre}}\right)$ or mature beta cells $\left(\mathrm{GR}^{\mathrm{RIPCre}}\right)$. Fetuses from normally fed pregnant females (white bars) and fetuses from food-restricted GFR females (black bars) were collected, their pancreas dissected and analysed and their body weight measured (e). Beta cell fraction was measured by quantitative morphometry after staining for insulin (a). Beta cell proliferation was measured after co-staining for insulin and BrdU and was expressed as the percentage of cells positive for insulin and BrdU over the total number of insulin cells. Individual values are plotted as white circles (normally fed control fetuses) or white squares

both in the fasted and fed states, with decreased fasting insulin levels; glucose intolerance was associated with a defect in glucose-stimulated insulin release but the offspring had normal peripheral insulin sensitivity. The hyperglycaemia and the hypoinsulinaemia are indicative of altered insulin secretion that could arise from a defect in beta cell mass and/or beta cell function. In F1-IUGR adult offspring, beta cell mass was markedly decreased, both in absolute terms and when expressed relative to body weight, even though the animals were smaller. Interestingly, alpha cell mass was also decreased as a consequence of decreased islet numbers with normal glucagon mRNA levels, suggesting that the amount of glucagon per cell was unchanged whereas that of insulin was decreased. In parallel, we showed that altered insulin secretion may arise from drastically decreased
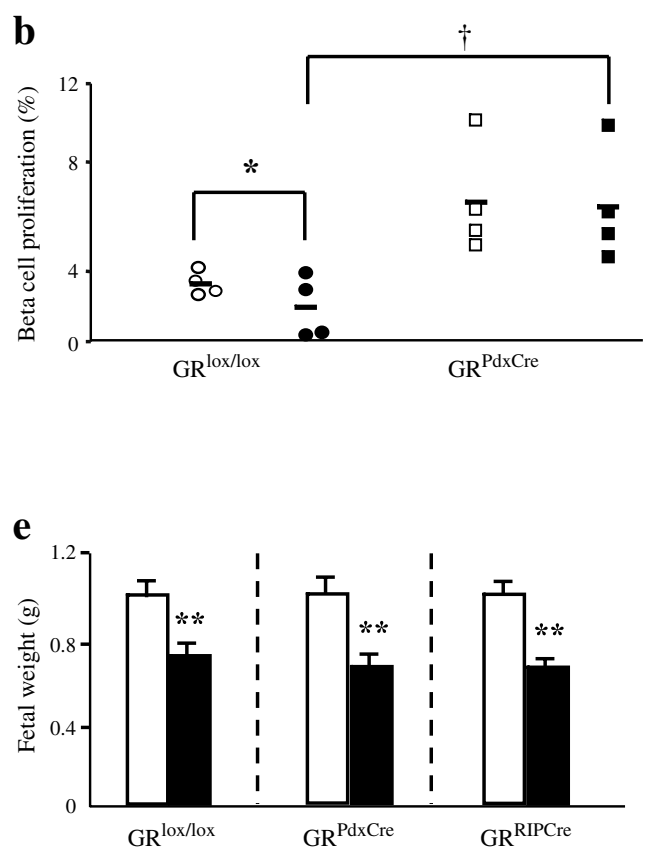

(normally fed $\mathrm{GR}^{\mathrm{PdxCre}}$ fetuses), and black circles or squares for foodrestricted control or $\mathrm{GR}^{\text {PdxCre }}$ fetuses, respectively (b). Representative pictures of beta cells stained for insulin (green) and BrdU (red) on pancreatic sections from a $\mathrm{GR}^{\text {lox/lox }}$ (c) and a $\mathrm{GR}^{\mathrm{PdxCre}}$ (d) fetus. Arrowheads point to cells positive for both insulin and BrdU. Maternal GFR (black bars) decreased fetal weight in all fetuses, and decreased beta cell fraction and proliferation in $\mathrm{GR}^{\text {lox/lox }}$ and $\mathrm{GR}^{\mathrm{RIPCre}}$ fetuses but not in $\mathrm{GR}^{\mathrm{PdxCre}}$ fetuses. ${ }^{*} p<0.05$ and ${ }^{* *} p<0.01$ when comparing GFR fetuses with normally fed control fetuses in each genotype using the Mann-Whitney test; ${ }^{\dagger} p<0.05$ and ${ }^{\dagger} p<0.01$ when comparing GR ${ }^{\text {PdxCre }}$ with $\mathrm{GR}^{\text {lox/lox }}$ under each respective set of nutritional conditions using the Mann-Whitney test. The results are expressed as means \pm SD $(n=7$ per group for fetal weight and $n=4$ for beta cell fraction and proliferation)

expression of several key beta cell function genes such as $P d x 1, N k x 2.2$, Ins 1 and Ins2 but also genes essential to glucose sensing such as Glut2, glucokinase and the subunits of ATP-sensitive $\mathrm{K}^{+}$channels Kir6.2 (the inwardly rectifying $\mathrm{K}^{+}$channel) and Surl (sulfonylurea receptor 1). Our model suggests that the metabolic phenotype of the adult offspring originates from a default of beta cell development in utero, resulting in a permanent reduction of beta cell mass and function, and leading to altered glucose homeostasis at an adult age.

A $50 \%$ reduction in maternal food intake during pregnancy led to decreased fetal weight from E14.5. Mouse pups were born with birthweight decreased by $20-30 \%$, a drastic reduction compared with the $15 \%$ reduction observed in the rat pups with the same diet [18]. This growth 
retardation persisted throughout life, was associated with decreased adiposity and had a more severe impact on males than females. Our data are in contrast to those of JimenezChillaron et al., [19] obtained using a murine model where in utero underfed offspring exhibit 'catch-up' growth, fed hyperinsulinaemia and develop glucose intolerance without reduction in beta cell mass. In this other model, the metabolic dysfunction of underfed offspring arises from the inability of islets to modulate insulin secretion relative to ambient glucose and a default of glucokinase/hexokinase activity. The reasons for the discrepancies between these two mouse models of 50\% maternal general food restriction are unclear, but the diet used here contains $5 \%$ fat whereas the diet used by the other group contains $9 \%$ fat. The difference between the two diets may affect fat storage in the mothers and modify fat content in the milk during suckling. In fact, the catch-up growth in the other model has been recently shown to be associated with increased gonadal fat, lipogenic gene expression and adipocyte size [20], whereas our adult animals showed decreased adiposity. Alternatively, the differences observed between the two models may also arise from the duration of food restriction, which in our model starts 1 day earlier [19].

In the present work, undernutrition was associated with increased maternal and fetal corticosterone concentrations that can be responsible for the programmed alterations of the fetal beta cells. In a previous study in rats, we adrenalectomised the dams to show the effect of maternal glucocorticoid elevation on fetal beta cell development [8]. Here, we used a more specific approach of genetic dissection in mice. We studied the impact of maternal undernutrition on genetically modified mice in which the GR is specifically deficient in either pancreatic precursor cells $\left(\mathrm{GR}^{\mathrm{PdxCre}}\right)$ or mature beta cells $\left(\mathrm{GR}^{\mathrm{RIPCre}}\right)$. As previously described in adults and neonates [16], the absence of GR in pancreatic precursors, but not in mature beta cells, increases fetal beta cell fraction in normally fed $\mathrm{GR}^{\text {PdxCre }}$ mutants and unexpectedly also increases beta cell proliferation. The ability of glucocorticoids to regulate cell proliferation plays an important role in their therapeutic anti-inflammatory and immunosuppressive effects, and further work is required to define the mechanisms involved in the upregulation of beta cell proliferation when glucocorticoid signalling is suppressed. An important issue to address is whether the effects of GFR on fetal beta cell fraction are mediated by the GR. Here, we clearly demonstrate that the deleterious effects of undernutrition and thereby excess glucocorticoid concentrations on beta cell expansion require the presence of the GR in the precursor cells. Moreover, the effects seen with $\mathrm{GR}^{\mathrm{PdxCr}}$ but not $\mathrm{GR}^{\mathrm{RIPCre}}$ indicate that GR signalling is important between progenitors and insulin-positive cells, though the precise stage at which this occurs is not yet clear. The data from the
GFR model showing decreased Ngn3 expression and increased exocrine markers suggest that it could be earlier than endocrine commitment, but the normal pancreas development seen at E15.5 in $\mathrm{GR}^{-/-}$mutants [21] makes this hypothesis rather unlikely and places the glucocorticoidsensitive period between E15.5 and E18.5 in the mouse.

Interestingly, undernutrition reduced fetal body weight in all groups of fetuses, irrespective of their genotype, underlining that suppression of glucocorticoid signalling in pancreatic precursor cells may protect and enhance beta cell mass but not fetal body weight during GFR, a result that was expected as the deletion of glucocorticoid signalling is pancreas specific. Unfortunately, the longterm metabolic and pancreatic consequences of fetal undernutrition could not be performed on these mutants because of their early postnatal death. So far, the reasons for the increased lethality in this mouse strain remain unclear and could be either maternal or fetal. In these mice, $50 \%$ food restriction may have stronger consequences than in the $\mathrm{CD} 1$ as $\mathrm{C} 57 \mathrm{BL} / 6$ mice are smaller and may have less energy storage capacity, preventing the dams from facing the increased metabolic demand of nurturing and lactating. Alternatively, fetal growth velocity seems to be more altered by undernutrition with the C57BL/6 genetic background, as mutant fetuses already show a profound growth retardation at E18.5 (-30\%) compared with $-20 \%$ in the CD1 fetuses at the same stage and with a similar gestation length. It is likely that this blunted growth is incompatible with postnatal life with the C57BL/6 genetic background.

In conclusion, we present here genetic evidence for the importance of glucocorticoid signalling in mediating the deleterious effects of undernutrition in programming fetal beta cell development. Low birthweight associated with excess glucocorticoid exposure during fetal life alters beta cell development, provided that the GR is present in the pancreatic precursors. This primitive impact of glucocorticoids on beta cell development permanently programmes the functional beta cell mass and thereby adult glucose tolerance. These results strengthen the notion that glucocorticoids are potent negative regulators of beta cell development and function in mice. Moreover, it suggests that humans who received dexamethasone treatment during fetal life in specific situations such as prevention of ambiguous genitalia in congenital adrenal hyperplasia syndrome [22] may undergo altered beta cell development, inasmuch as both the production of cortisol de novo by the human fetus and the expression of the GR in the human fetal pancreas occur at exactly the same time as pancreatic progenitors are committing to the endocrine lineage [23, 24]. These individuals treated in utero with glucocorticoids may consequently be at increased risk of developing diabetes later in life and should therefore be followed closely. 
Acknowledgements We thank P. Herrera (Department of Genetic Medicine and Development, Faculty of Medicine, University of Geneva, Geneva, Switzerland), who initially provided the Pdx-Cre and RIP-Cre mouse lines. We thank P. Letteron for his technical assistance on the Piximus and E. Gesina for training and support. B. Valtat is a recipient of a fellowship from the Ministère de l'Enseignement Supérieur et de la Recherche and B. Blondeau received financial support from the European Foundation for the Study of Diabetes (EFSD). Support for these studies was provided by the European Union (FP6 Earnest Programme Food-CT-2005-007036) and the Agence Nationale de la Recherche (ANR) Grant gramsy no. A05245DS to B. Bréant and F. Tronche.

Duality of interest The authors declare that there is no duality of interest associated with the manuscript.

\section{References}

1. Barker DJ (1998) In utero programming of chronic disease. Clin Sci (Lond) 95:115-128

2. Hales CN, Barker DJ, Clark PM et al (1991) Fetal and infant growth and impaired glucose tolerance at age 64. BMJ 303:10191022

3. Lithell HO, McKeigue PM, Berglund L, Mohsen R, Lithell UB, Leon DA (1996) Relation of size at birth to non-insulin dependent diabetes and insulin concentrations in men aged 50-60 years. BMJ 312:406-410

4. McMillen IC, Robinson JS (2005) Developmental origins of the metabolic syndrome: prediction, plasticity, and programming. Physiol Rev 85:571-633

5. Edwards CR, Benediktsson R, Lindsay RS, Seckl JR (1993) Dysfunction of placental glucocorticoid barrier: link between fetal environment and adult hypertension? Lancet 341:355-357

6. Cottrell EC, Seckl JR (2009) Prenatal stress, glucocorticoids and the programming of adult disease. Front Behav Neurosci 3:19

7. Reinisch JM, Simon NG, Karow WG, Gandelman R (1978) Prenatal exposure to prednisone in humans and animals retards intrauterine growth. Science 202:436-438

8. Blondeau B, Lesage J, Czernichow P, Dupouy JP, Breant B (2001) Glucocorticoids impair fetal beta cell development in rats. Am J Physiol Endocrinol Metab 281:E592-E599

9. Lesage J, Blondeau B, Grino M, Breant B, Dupouy JP (2001) Maternal undernutrition during late gestation induces fetal overexposure to glucocorticoids and intrauterine growth retardation, and disturbs the hypothalamo-pituitary adrenal axis in the newborn rat. Endocrinology 142:1692-1702
10. Lindsay RS, Lindsay RM, Waddell BJ, Seckl JR (1996) Prenatal glucocorticoid exposure leads to offspring hyperglycaemia in the rat: studies with the 11 betahydroxysteroid dehydrogenase inhibitor carbenoxolone. Diabetologia 39:1299-1305

11. Nyirenda MJ, Lindsay RS, Kenyon CJ, Burchell A, Seckl JR (1998) Glucocorticoid exposure in late gestation permanently programs rat hepatic phosphoenolpyruvate carboxykinase and glucocorticoid receptor expression and causes glucose intolerance in adult offspring. J Clin Invest 101:2174-2181

12. de Vries A, Holmes MC, Heijnis A et al (2007) Prenatal dexamethasone exposure induces changes in nonhuman primate offspring cardiometabolic and hypothalamic-pituitary-adrenal axis function. J Clin Invest 117:1058-1067

13. Nyirenda MJ, Carter R, Tang JI et al (2009) Prenatal programming of metabolic syndrome in the common marmoset is associated with increased expression of 11 beta-hydroxysteroid dehydrogenase type 1. Diabetes 58:2873-2879

14. Garofano A, Czernichow P, Breant B (1997) In utero undernutrition impairs rat beta cell development. Diabetologia 40:1231-1234

15. Garofano A, Czernichow P, Bréant B (1999) Effect of ageing on beta cell mass and function in rats malnourished during the perinatal period. Diabetologia 42:711-718

16. Gesina E, Tronche F, Herrera P et al (2004) Dissecting the role of glucocorticoids on pancreas development. Diabetes 53:2322-2329

17. Avril I, Blondeau B, Duchene B, Czernichow P, Breant B (2002) Decreased beta cell proliferation impairs the adaptation to pregnancy in rats malnourished during perinatal life. J Endocrinol 174:215-223

18. Garofano A, Czernichow P, Breant B (1998) Beta cell mass and proliferation following late fetal and early postnatal malnutrition in the rat. Diabetologia 41:1114-1120

19. Jimenez-Chillaron JC, Hernandez-Valencia M, Reamer C et al (2005) Beta cell secretory dysfunction in the pathogenesis of low birthweight-associated diabetes: a murine model. Diabetes $54: 702-711$

20. Isganaitis E, Jimenez-Chillaron J, Woo M et al (2009) Accelerated postnatal growth increases lipogenic gene expression and adipocyte size in low-birthweight mice. Diabetes 58:1192-1200

21. Gesina E, Blondeau B, Milet A et al (2006) Glucocorticoid signalling affects pancreatic development through both direct and indirect effects. Diabetologia 49:2939-2947

22. Lajic S, Nordenstrom A, Hirvikoski T (2008) Long-term outcome of prenatal treatment of congenital adrenal hyperplasia. Endocr Dev 13:82-98

23. Goto M, Piper Hanley K, Marcos J et al (2006) In humans, early cortisol biosynthesis provides a mechanism to safeguard female sexual development. J Clin Invest 116:953-960

24. Phan-Hug F, Guimiot F, Lelievre V et al (2008) Potential role of glucocorticoid signaling in the formation of pancreatic islets in the human fetus. Pediatr Res 64:346-351 